Angela Almašiová, Katarína Kohutova

Slovak Republic

Alina Budniak

Poland

\title{
School Burnout Syndrome in the Students of Helping Professions and its Possible Predictors
}

DOI: 10.15804/tner.2019.57.3.03

\begin{abstract}
This paper deals with the burnout syndrome among students in the context of selected demographic characteristics of respondents, frequented level of study, satisfaction with the study, frequented study program, study performance and the vision for their future careers. The study aims to identify the possible predictors of the burnout syndrome among the students and identify the risk groups of students. Altogether 350 students from the Faculty of Education participated in the research, and the SBI (School Burnout Inventory) questionnaire was used to measure the burnout syndrome. The main findings include the rate of school burnout, with almost $18 \%$ of students exhibiting a high level. Using the method of classification trees, variables such as age and the overall satisfaction rate with the study were identified as predictors on the "Cynicism" subscale; grade average, age and field of study on the "Inadequacy" subscale, and no predictor was identified on the "Emotional Exhaustion" subscale. These results were complemented by qualitative interviews with the students and a teacher training specialist.
\end{abstract}

Keywords: burnout syndrome, stress disorder, emotional exhaustion, social support

\section{Introduction}

The burnout syndrome is a well-studied area in the context of helping professions. One of the first tools that was used to measure the burnout syndrome was the questionnaire introduced by the authors Christina Maslach and Susan E. Jack- 
son MBI (Maslach Burnout Inventory). The burnout syndrome was described as a syndrome of emotional exhaustion and cynicism that often occurs among the individuals engaged in helping professions (Maslach, Jackson, 1981). The main aspect of burnout, according to the authors, is emotional exhaustion caused by the depletion of resources; another aspect is the development of negative feelings towards the clients, and the third aspect is own self-assessment, which is based on personal unhappiness and a sense of dissatisfaction with the work. Based on the above, the authors made a questionnaire with three subscales focusing on the individual aspects of the burnout syndrome, and highlighted the correlation between the burnout syndrome and physical exhaustion, insomnia, alcohol and drug use and various kinds of relationship problems (Maslach, Jackson, 1981). Although the beginnings of the burnout syndrome analysis are associated mainly with the performance of helping professions, it can also be noticed in the performance of other social roles, for example, it can be connected with college study (Shin, 2011, Dyrbye et al., 2009; Hernesniemi et al., 2017; Kuittinen a Meriläinen, 2011; Zarobkiewicz, et al., 2018, Nikodijević, Labrović, Doković, 2012; Stein, Sibanda, 2016; Ried, et al. 2006, Merino-Tejedor. et al., 2015, Aghajari et al., 2018). Various studies use different terminology to label this concept: academic burnout, student burnout, student academic burnout, school burnout. For the purposes of the present paper, we will use the term "school burnout" or "school burnout syndrome".

School burnout is a stress disorder associated with the school that can, according to Salmela-Aro et al., (2009), occur in three dimensions: cynicism and detached attitude towards school (manifested by indifference and detached attitude to school); emotional exhaustion (as the basic individual stress item of the syndrome) and a feeling of inadequacy as a student (this relates to the limited sense of competence and academic achievements). School burnout can be caused by multiple reasons. According to Salmela-Aro et al (2008), it can be due to the school itself, or personality and demographic characteristics. In our research, we focused on both types of reasons.

To measure school burnout, researchers use a variety of tools: MBI SS (Maslach Burnout Inventory-Student Survey); Copenhagen Burnout Inventory, SBI (School Burnout Inventory) is used most commonly.

The consequences of burnout among students are linked to different aspects such as cancellation of enrollment in courses, poor academic results and a negative attitude to the university (Neumann et al, 1990), and lack of engagement in student life (Schaufeli et al, 2002). A meta-analysis conducted on 19 studies showed a strong negative correlation between the school burnout syndrome and 
social support - social support especially from the schools and teachers, with a significant role of the parents and peers (Kim et al., 2018).

\section{Research Methodology}

The main objective of our research was to determine the rate of school burnout, to identify the possible predictors of the school burnout syndrome and the at-risk students. This objective was materialized through the quantitative strategy of the questionnaire. The questionnaire was based on the SBI (School Burnout Inventory) by Salmela-Aro et al. (2009), which was translated and adapted by Ms. Pechancová ${ }^{1}$ Each item was assessed by the respondents on a 5-point Likert scale ( 1 = strongly agree, $5=$ strongly disagree). The individual items fall into three subscales - "Emotional Exhaustion", "Cynicism and Detached Attitude to School" and "Feelings of Inadequacy as a Student". Additionally, the questionnaire included demographic questions and questions relating to the overall satisfaction with the study, the future profession and the respondent's study average.

Another objective of our research was to investigate the subjective view of the respondents on the school burnout syndrome, its possible sources and the position of the teacher in the emergence of the school burnout syndrome. This objective was realized through a qualitative strategy by conducting interviews with the respondents (both students - future teachers, and a teacher training specialist).

\section{Research Sample}

The quantitative part of our research sample consisted of 350 respondents - students of Social Work (19.4\%, N = 68), Special Education and Education of Mentally Handicapped Students (44.9\%, N = 157) and Preschool and Elementary Education $(35.7 \%, \mathrm{~N}=125)$ at the Faculty of Education. The research sample consisted of 36 (10.3\%) men and $314(89.7 \%)$ women. The average age of the respondents was 24.57 years, the sample had a median of 23 , modus of 22 , standard deviation of 6.56 , minimum age was 19 and maximum age was 54 . The weighted study average was indicated by the respondents as follows: weighted average 1.0 was indicated by $4.6 \%$ (16) of the respondents, weighted average from 1.1 to 2.0 was indicated

1 The author followed the relevant principles to adapt foreign methods - translation into Czech, re-translation into English, and editing of the items. 
by $71.1 \%$ (249) of the respondents, weighted average of 2.1 to 3.0 was indicated by $21.4 \%(75)$ of the respondents, and weighted average of above 3.1 was indicated by $2.9 \%$ (10) of the respondents.

The qualitative part of the interview was attended by 13 respondents - students at the Faculty of Education, and one teacher training specialist.

\section{Instrument and Procedure}

To process the results in the quantitative section, statistical procedures of descriptive statistics - calculation of frequency $(\mathrm{N})$ and percentages (\%), mean, standard deviation (SD), and inferential statistics procedures - parametric and non-parametric tests, were used. To determine the predictors, we used the CHAID classification tree method. All tests were performed at a significance level of $\alpha=$ 0.05 and were implemented in SPSS 21.0.

\section{Results}

\section{Quantitative part}

Chart 1 shows the average values of the individual items making up the total burnout syndrome according to the SBI questionnaire (the higher the average, the higher the school burnout syndrome value, using a 5-point Likert scale).

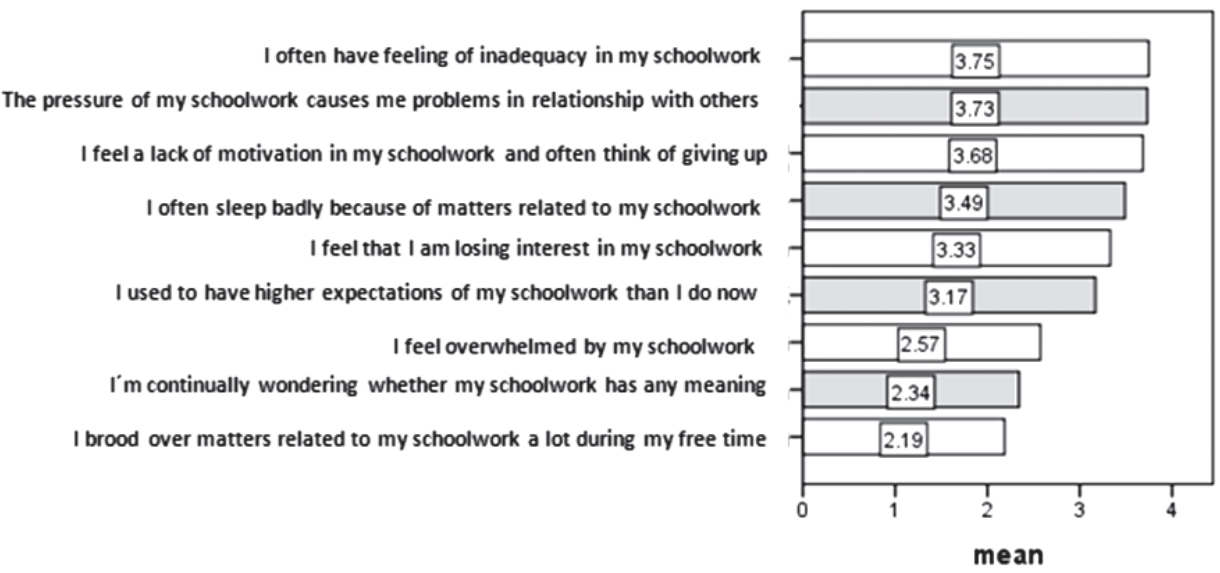

Chart 1. The average value of the SBI questionnaire items 
The average score of school burnout in the students at the Faculty of Education on the SBI scale was $28.2 \pm 5.4$; minimum 8 , maximum 38. After determining the school syndrome levels (average burnout $=$ mean \pm standard deviation, low burnout syndrome $=$ value below average, and high burnout syndrome $=$ value above average), the results were shown as follows. The low burnout syndrome is exhibited in $16,9 \%$ of the respondents, the average school burnout syndrome can be observed in $65.4 \%$ of the respondents, and the high school burnout syndrome was reported by $17.7 \%$ of the respondents.

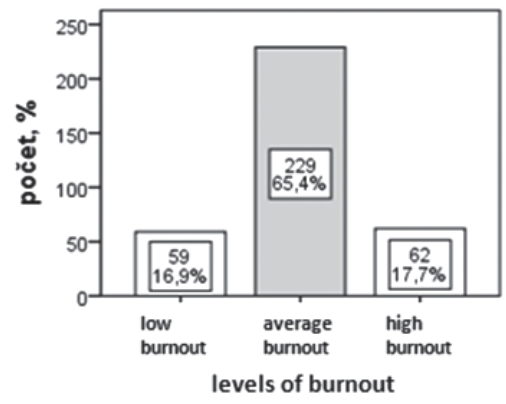

Chart 2. Levels of the burnout syndrome in the respondents

In the following analyses, we distributed the questionnaire items into the individual subscales - "Emotional Exhaustion"; "Cynicism and Detached Attitude to School" and "Feelings of Inadequacy as a Student", which were first compared with the demographic characteristics - age and sex, field of study and level of study (Table 1). Gender has not proven to be a distinguishing factor among the respondents and the individual components of the school burnout syndrome none of the subscales have shown any statistically significant difference between girls and boys. The field of the study factor has demonstrated differences on the "Feelings of Inadequacy as a Student" subscale, and after the post-hoc test (Tukey), differences were noted between Special Education students and Preschool and Elementary Education students. In the level of the study category, the difference was also shown in the "Feelings of Inadequacy as a Student" subscale, with higher average burnout values in Masters students.

The subsequent analyses included factors such as overall satisfaction with the study (the respondents were to express their satisfaction on a 5-point scale where $1=$ very dissatisfied and $5=$ very satisfied), weighted grade average and the vision of the future profession (the respondents were to express whether they intend to 
Table 1. A comparison of SBI subscales according to gender, the field of study and the level of study

\begin{tabular}{lcccc}
\hline \multicolumn{1}{c}{ Gender } & EE & C & I & Total \\
\hline Male (average \pm SD) & $11.7(2.9)$ & $9.6(2.0)$ & $7.0(1.9)$ & $28.4(5.2)$ \\
\hline Female (average \pm SD) & $12.0(2.9)$ & $9.3(2.1)$ & $6.9(2.2)$ & $28.2(5.4)$ \\
\hline $\mathrm{p}^{*}$ & 0.542 & 0.447 & 0.721 & 0.938 \\
\hline Field of study & & & & \\
\hline SE (average \pm SD) & $12.1(2.9)$ & $9.3(9.2)$ & $7.2(2.3)$ & $28.7(5.6)$ \\
\hline PEE (average \pm SD) & $11.7(2.9)$ & $9.4(2.1)$ & $6.5(2.2)$ & $27.6(5.6)$ \\
\hline SW (average \pm SD) & $12.2(2.5)$ & $9.5(1.8)$ & $6.8(1.8)$ & $28.6(4.4)$ \\
\hline $\mathrm{p}^{* *}$ & 0.388 & 0.691 & $\mathbf{0 . 0 0 8}$ & 0.195 \\
\hline Level of study & & & & \\
\hline BA (average $\pm S D)$ & $12.2(2.9)$ & $9.6(2.1)$ & $6.7(2.1)$ & $28.4(5.4)$ \\
\hline MA (average \pm SD) & $11.8(2.8)$ & $9.2(2.1)$ & $7.1(2.2)$ & $28.1(5.4)$ \\
\hline $\mathrm{p}^{*}$ & 0.215 & 0.067 & $\mathbf{0 . 0 4 8}$ & 0.589 \\
\hline
\end{tabular}

$\mathrm{EE}=$ "Emotional Exhaustion"; C = cynicism; I = "Feelings of Inadequacy as a Student"; $\mathrm{SE}=$ Special Education; PEP = Preschool and Elementary Education; SW = Social Work; ${ }^{*} \mathrm{p}$ value in the Mann-Whitney $\mathrm{U}$-test; ${ }^{* *} \mathrm{p}$ value in ANOVA

pursue the profession they study at the university). The overall satisfaction with the study is a factor that correlates with the "Cynicism" and "Feelings of Inadequacy as a Student" subscale. The higher the overall satisfaction with the study, the higher the burnout syndrome in both above subscales. In the case of the study results, a significant correlation was also shown in the "Cynicism" and "Feelings of Inadequacy as a Student" subscale. The worse the study results, the more intense the burnout in the areas outlined above.

Table 2. A comparison of SBI subscales with respect to the satisfaction with the study, the study results and the vision of the future career

\begin{tabular}{lcccc}
\hline \multicolumn{1}{c}{ Satisfaction with study } & EE & C & I & Total \\
\hline Correlation coefficient & 0.068 & $0.343^{\star *}$ & $0.345^{\star *}$ & $0.320^{\star *}$ \\
\hline $\mathrm{p} \quad$ & 0.581 & 0.004 & 0.004 & 0.008 \\
\hline \multicolumn{1}{c}{ Study results } & & & & \\
\hline Correlation coefficient & 0.045 & $-0.385^{\star *}$ & $-0.353^{* *}$ & -0.218 \\
\hline $\mathrm{p}$ & 0.718 & $\mathbf{0 . 0 0 1}$ & $\mathbf{0 . 0 0 3}$ & 0.074 \\
\hline
\end{tabular}


School Burnout Syndrome in the Students of Helping Professions and its Possible Predictors 45

\begin{tabular}{lcccc}
\hline \multicolumn{1}{c}{ Satisfaction with study } & EE & C & I & Total \\
\hline \multicolumn{1}{c}{ Vision of future career } & & & & \\
\hline Yes (average \pm SD) & $12.4(2.0)$ & $9.9(1.5)$ & $6.7(1.7)$ & $28.4(5.4)$ \\
\hline No (average \pm SD) & $12.3(2.8)$ & $8.9(2.3)$ & $6.4(1.9)$ & $28.3(4.8)$ \\
\hline $\mathrm{p}^{*}$ & $\mathbf{0 . 0 2 2}$ & 0.090 & 0.464 & 0.877 \\
\hline
\end{tabular}

$\mathrm{EE}=$ "Emotional Exhaustion"; C = cynicism; I = "Feelings of Inadequacy as a Student";

${ }^{*}$ correlation is significant at a level of $0.001 ; \mathrm{p}^{*}$ Mann-Whitney U-test value

\section{Predictors of students' burnout on the SBI subscales (risk groups of students in the context of the school burnout syndrome)}

The method of classification trees was used to identify the predictors of the burnout syndrome and the student risk groups in the context of the school burnout syndrome in each subscale. This method is used, for example, to identify the respondents belonging to a particular group, to assign the respondents into individual categories, and to predict the future events etc. The CHAID algorithm was used in the analysis. The individual burnout syndrome variables were used in the algorithm as dependent variables, and age, gender, study program, overall satisfaction with the study, weighted grade average and the vision of the future career of the respondent were used as independent variables. In the case of "Emotional Exhaustion" subscale, the algorithm did not identify any variable that would have predicted it. In the case of "Cynicism", the most discriminating variable was age - younger respondents had higher burnout rates (mean $=9.6$ ) than older respondents (mean $=8.4$ ). For younger respondents, the node branches: it is discriminated by the overall level of satisfaction with the study - the dissatisfied respondents have a higher burnout rate (mean $=10.1$ ) and conversely, the satisfied respondents have a lower burnout rate (mean $=9.0$ ). Both nodes are final. In terms of risk, the youngest respondents who are generally dissatisfied with the study appear to be most at risk.

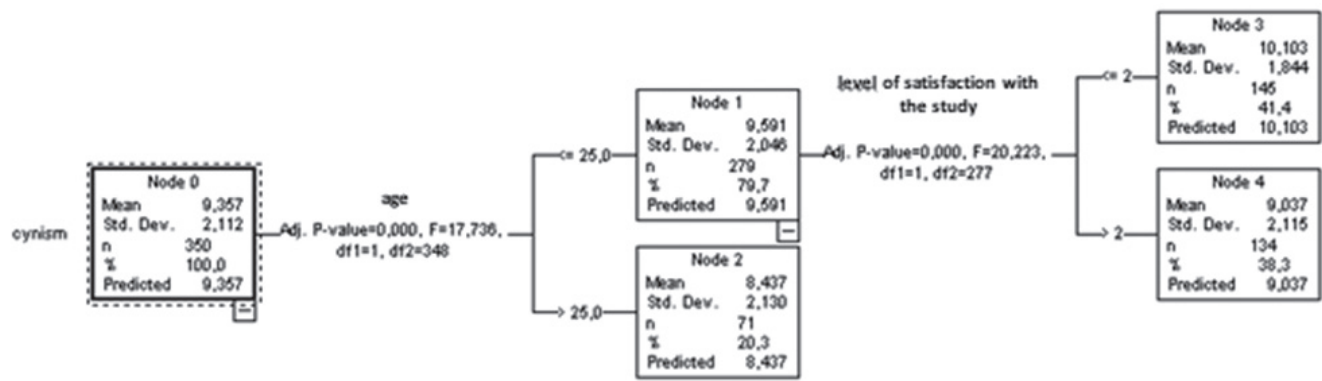

Chart 3. A classification tree of the "Cynicism" subscale 
In the case of "Feelings of Inadequacy as a Student" subscale, weighted grade average is the most discriminating variable. The students with worse study results (mean $=6.1)$ exhibit burnout to a lesser degree than the ones with better results (mean $=7.2)$ - this node is final. In the case of the students with better averages,

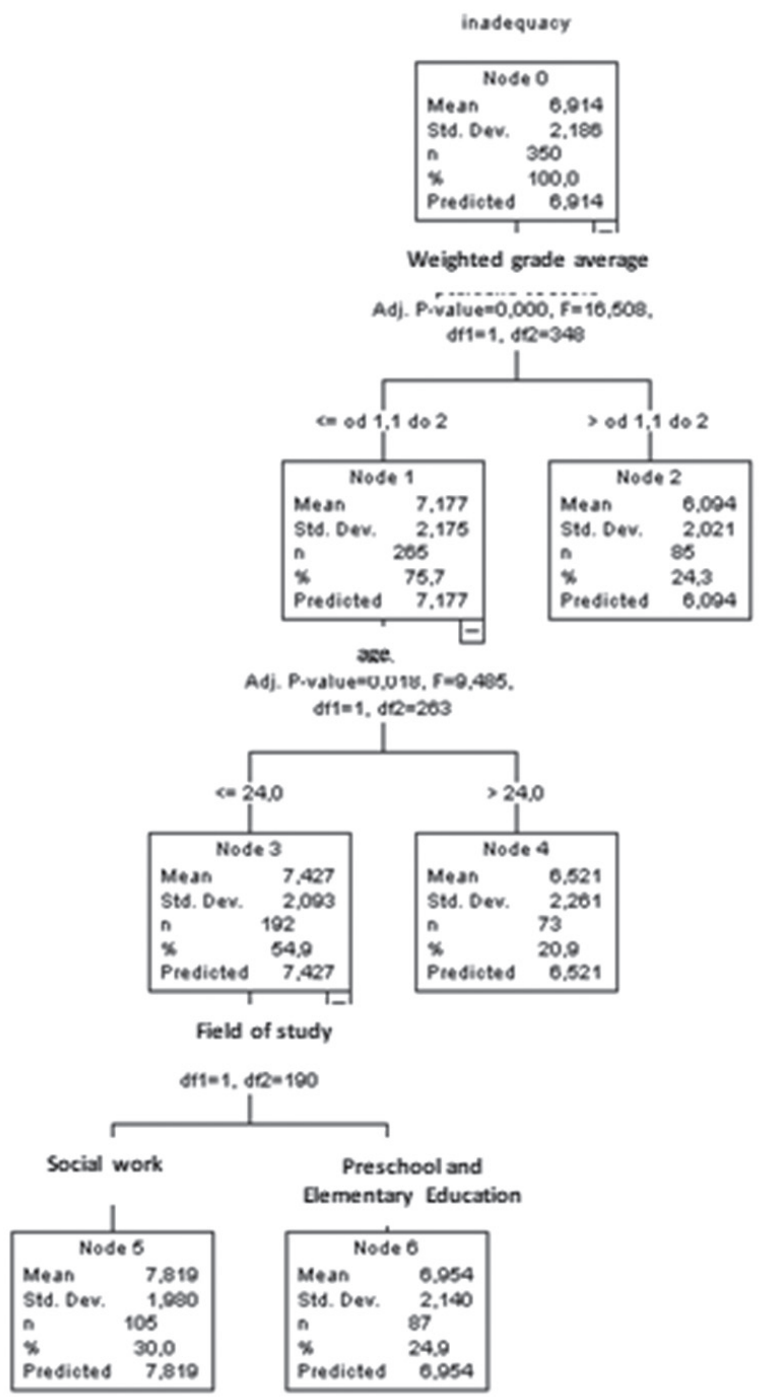

Chart 4. A classification tree of the "Feelings of Inadequacy as a Student" subscale 
the node branches based on age - older students exhibited lower levels of burnout than younger students, which are in turn discriminated by the field of study, with the students of Social Work and Special Education, having higher burnout levels than the students of Preschool and Elementary Education. In terms of risk, the most vulnerable students are the students of Social Work and Special Education under the age of 24 , and with better academic results.

\section{Qualitative part}

\section{Selected analysis - An interview with students and teacher training specialist}

Besides the above quantitative research, which was implemented through a questionnaire, we also conducted qualitative interviews with the students, which enabled us to better understand the problems associated with the school burnout syndrome. We present the following key findings from the interviews:

\section{Have you noticed any of the symptoms of the burnout syndrome during the study?}

Only a few respondents did not experience any of the various symptoms of the school burnout syndrome. The most commonly reported symptoms included emotional exhaustion associated with the family and employer pressure (in the case where the respondent was employed), some respondents reported "reduced self-esteem and hopelessness", "complete reluctance to go to lectures and learn", and even somatization of the burnout syndrome and physical problems: "I felt fatigue, decreased performance and lack of sleep because I had to think about my school assignments and how to do them". The respondents who reported no burnout syndrome provided different answers: "I never noticed it, I study well and have no problems", "No, I never felt it", "No, not in me, but I see it in my classmates - they struggle with the study and have problems of this nature."

\section{What in your opinion causes the school burnout? What reasons are key?}

The most commonly reported reasons that cause burnout in the respondents were external reasons: "Student overload with excessive levels of responsibility (many courses per semester) and dwindling expectations and disappointment once at the university". The external reasons for the school burnout syndrome also includes the behavior of the teacher: "Low motivation to study on the part of teachers", "Poor cooperation with teachers and lacking feedback". The respondents also highlighted 
the Slovak university education system: "Malfunctioning education system", but also "low status of the study program". The internal root causes of burnout included "lack of mental hygiene", "poor diet", but also a combination of internal and external sources: "high pressure on the students to study particular issues that they themselves consider to be futile and useless". In part-time students, the burnout syndrome is caused by the inability to reconcile family life and school obligations: "a lot of study assignments and duties, a lot of responsibilities at work - and taking care of family and children", "a lot of responsibilities at school and at work".

\section{What responsibilities, strategies and activities do you implement to eliminate or prevent school burnout?}

The respondents use various strategies and methods, e.g. physical activity, to eliminate school burnout. "I do sports to dissipate stress", "I hike in the woods", "I personally go for a walk with my family and have the support of my husband, which helps me in the times of trouble at school" but also various other forms: "autogenous training", "family and doing what fills me (my hobbies)", "relaxation and therapy". Some respondents also included the school to this question, which in their opinion should: "involve the students into its activities", "foster the loyalty of its students", "ensure more support from the teachers" and "provide counseling for the students".

\section{What role in the school burnout is played by the teacher?}

According to all the surveyed respondents, the teacher plays an important role in school burnout. Some respondents described the positive impact of the teachers in their answers: "... a very big role. One has a very different approach to those subjects where the teachers can discuss the issue interestingly and yet manage to build respect through their expertise". "A very important role - if the teacher is empathetic, attentive and fair, it reduces the likelihood of burnout". On the contrary, some respondents voiced the possible negative influence of the teacher on the school burnout syndrome: "If the teacher demands much from the students, it may happen that the students simply burn out". "An important role - the more demotivating the teachers are, the more it affects the students".

The interview with the teacher training specialist prof. E. Petlák showed that the school burnout syndrome is an area that is relatively unrecognized in our country with regard to university students and it is extremely important that it be researched in a relevant way. One interview with the respondent also posed the question of the root causes of burnout. In his view, these include the high demands of university study, complexity of requirements of the individual fields 
of study, and an effort and desire to succeed already during the study to get a good job. The most interesting is the statement about a continuous reduction of demands during the admission process at the faculties of education and the related lack of desirable intellectual and cognitive equipment of the students, which can also result in the school burnout syndrome. In any case, the above reasons may be important predictors of school burnout, which can be verified with a further empirical research.

\section{Discussion and conclusions}

The results of our research show that the majority of students $(65.4 \%)$ have an average degree of burnout, nearly $17 \%$ of the students have a low degree of school burnout, and $17.7 \%$ of the students have a high degree of school burnout. In comparison, the research results presented by other authors show that in a set of 545 respondents (students of medicine in the United States), $45 \%$ of the students suffer from burnout (Dyrbye et al., 2006), Samela-Aro, Hernesniemi et al. (2017) found that $33 \%$ of the students are at risk of burnout among Finnish university students (2427 respondents), and Kuittinen Meriläinen (2011) identified the burnout risk in $45 \%$ of Finnish students (set of 3031 respondents).

The differences of the burnout syndrome subscale in each school did not show in terms of gender, and they only showed in the "Feelings of Inadequacy as a Student" subscale in relation to the field of study. In relation to the field of study, differences were noted on the "Feelings of Inadequacy as a Student" subscale between the Special Education students and Preschool and Elementary Education students. Research aimed at detecting the differences between the field of study was carried out e.g. by Škodová and Bánovčinová (2011), which found higher burnout among the students of medical disciplines than non-medical fields. Similarly, Majerníková and Obročníková (2017) compared the study of nursing and midwifery and found that the difference proved to be significant - a lesser degree of burnout is noted in the students of nursing. Among the other variables that affect the differences in the individual subscales we can mention e.g. satisfaction with the study and study results ("Cynicism" and "Inadequacy as a Student") and the vision of future career ("Emotional Exhaustion").

The following predictors of school burnout were identified in each subscale:

- "Cynicism and Detached Attitude to School": age and level of satisfaction with the study. Risk groups: younger respondents who are generally dissatisfied with the study. 
- "Feelings of Inadequacy as a Student": grade average, age and field of study. Risk groups: students of Social Work and Special Education, 24 years and younger, with a better grade average.

The satisfaction rate with the study was manifested as one of the risk predictors of burnout. If we view study satisfaction mainly within the context of fulfilling the students' expectations, the universities should try to know the needs of their students and respond to these needs in a competitive environment as part of maintaining a quality university environment. In their research, Wulandari and Jager (2018) point to the importance of finding a balance between the students' expectations, the mission of the university or college and the importance of possible feedback from the students.

The interviews with the respondents showed a great influence of the teachers on the school burnout syndrome, which was also presented by Kim et al. (2018) in his study. The authors report a strong social support from school, teachers, family and peers as a very important predictor. These two groups of social support providers have proven to be equally important in our interviews. The importance of quality school environment in the educational process is also emphasized by Petlák, Tištanová and Juszczyk (2019) in their research.

The research identified the predictors and high-risk groups of students that are most threatened by the school burnout syndrome. In the university study, it is necessary to take steps to ensure that these students have access to sociopsychological support to prevent the emergence and development of burnout. One of the solutions proposed by us is to understand the expectations of the students, which should be regularly monitored and incorporated into the operations in accordance with the mission of each university.

\section{References}

Aghajari, Z. et al. (2018) The relationship between quality of learning experiences and academic burnout among nursing students of Shahid Beheshti University of Medical Sciences in 2015. Electronic Journal of General Medicine, 15(6), pp. 1-10. doi: 10.29333/ ejgm/93470.

Dyrbye L.N., Thomas M.R., Huntington J.L., Lawson K.L., Novotny P.J., Sloan J.A., Shanafelt T.D. (2006) Personal life events and medical student well-being: a multicentre study. Acad Med, 2006;81 (4):374-84.

Dyrbye, L.N., Thomas, M.R., Harper, W. , Massie, F.S., Power, D.V., Eacker, A., Szydlo, D.W., Novotny, P.J., Sloan, J.A. and Shanafelt, T.D. (2009) The learning environment and medical student burnout: a multicentre study. Medical Education, 43: 274-282. doi:10.1111/j.1365-2923.2008.03282.x

Hernesniemi, E., Räty, H., Kasanen, K., Cheng, X., Hong, J. \& Kuittinen, M. (2017) Burnout 
among Finnish and Chinese university students. Scandinavian Journal of Psychology $58,400-408$.

Kim, B. et al. (2018) Relationships between social support and student burnout: A meta-analytic approach. Stress \& Health: Journal of the International Society for the Investigation of Stress, 34(1), pp. 127-134. doi: 10.1002/smi.2771.

Kuittinen, M. \& Meriläinen, M. (2011) The effect of study-related burnout on student perceptions. Journal of International Education in Business, 4, 42-62.

Majerníková, L., Obročníková, A. (2017) Personality predictors and their impact on coping with burnout among students preparing for the nursing and midwifery profession. Kontakt, Volume 19, Issue 2, 2017, Pages 93-98, ISSN 1212-4117.

Maslach, C., \& Jackson, S.E. (1981) The measurement of experienced burnout. Journal of Occupational Behavior, 2(2), 99-113. https://doi.org/10.1002/job.4030020205.

Merino-Tejedor, E. et al. (2015) Adaptation and psychometric properties of the SBI-U scale for Academic Burnout in university students. Anales de Psicología, 31(1), pp. 290-297. doi: 10.6018/analesps.31.1.168581.

Neumann, Y., Finaly-Neumann, E. and Reichel, A. (1990) Determinants and consequences of students' burnout inuniversities. Journal of Higher Education, 61(1), 20-31.

Nikodijević, A., Labrović, J.A. and Doković, A. (2012) Academic Burnout Among Students at Faculty of Organizational Sciences. Management (1820-0222), (64), pp. 47-53. doi: 10.7595/management.fon.2012.0019.

Petlák, E., Tištanová, K., Juszczyk, S. (2019) Undesirable Behaviour of Pupils Towards Teachers in Slovak Schools. The New Educational Review, Vol. 55, No. 1. pp. 170-184.

Ried, L.D. et al. (2006) Comparing Self-reported Burnout of Pharmacy Students on the Founding Campus With Those at Distance Campuses. American Journal of Pharmaceutical Education, 70(5), pp. 1-12. doi: 10.5688/aj7005114.

Salmela-Aro, k., et al. (2009) School Burnout Inventory. Reliabilty and Validity. European Journal of Psychological Assessment, 25, pp. 48-57.

Shin, H., Puig, A., Lee, J. et al. (2011). Cultural validation of the Maslach Burnout Inventory for Korean students. Asia Pacific Educ. Rev. 12: 633. https://doi.org/10.1007/s12564-011-9164-y

Schaufeli, W.B., Martinez, I.M., Marques Pinto, A.,Salanova, M. and Bakker, A.B. (2002) Burnout and engagement in university students: a cross-national study. Journal of Cross-Cultural Psychology, 33, 464-81.

Stein, C. and Sibanda, T. (2016) Burnout among paramedic students at a university in Johannesburg, South Africa. African Journal of Health Professions Education, 8(2), pp. 193-195. doi: 10.7196/AJHPE.2016.v8i2.626.

Škodová, Z., Bánovčinová, L. (2011) Osobnostné prediktory syndrómu vyhorenia u študentov pomáhajúcich profesii (Personality predictors of burnout among the students of helping professions). Nursing and Midwifery. Issue 2, no. 4/ 201.

Wulandari, N., Jager, J.W. (2018) Students' Expectations of Higher Educational Experience in Public vs. Private Universities in Indonesia. The New Educational Review, Vol. 54, No. 4. pp. 146-156.

Zarobkiewicz, M.K. et al. (2018) Burnout among students of medical universities in Poland. Polish Journal of Public Health, 128(1), pp. 26-29. doi: 10.2478/pjph-2018-0005. 